\title{
A Three-Dimensional Mechanical Loading Model of Human Osteocytes in Their Native Matrix
}

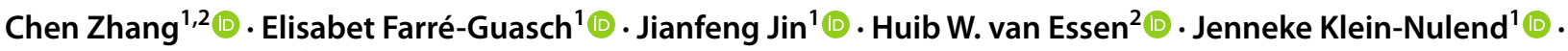 \\ Nathalie Bravenboer ${ }^{2}$ (D)
}

Received: 25 June 2021 / Accepted: 20 September 2021 / Published online: 13 October 2021

(c) The Author(s) 2021

\begin{abstract}
Osteocytes are mechanosensory cells which are embedded in calcified collagenous matrix. The specific native matrix of osteocytes affects their regulatory activity, i.e., transmission of signaling molecules to osteoclasts and/or osteoblasts, in the mechanical adaptation of bone. Unfortunately, no existing in vitro model of cortical bone is currently available to study the mechanosensory function of human osteocytes in their native matrix. Therefore, we aimed to develop an in vitro threedimensional mechanical loading model of human osteocytes in their native matrix. Human cortical bone explants containing osteocytes in their three-dimensional native matrix were cultured and mechanically loaded by three-point bending using a custom-made loading apparatus generating sinusoidal displacement. Osteocyte viability and sclerostin expression were measured 1-2 days before 5 min loading and 1 day after loading. Bone microdamage was visualized and quantified by micro$\mathrm{CT}$ analysis and histology using $\mathrm{BaSO}_{4}$ staining. A linear relationship was found between loading magnitude $(2302-13,811$ $\mu \varepsilon)$ and force (1.6-4.9 N) exerted on the bone explants. At $24 \mathrm{~h}$ post-loading, osteocyte viability was not affected by 1600 $\mu \varepsilon$ loading. Sclerostin expression and bone microdamage were unaffected by loading up to $8000 \mu \varepsilon$. In conclusion, we developed an in vitro 3D mechanical loading model to study mechanoresponsiveness of viable osteocytes residing in their native matrix. This model is suitable to study the effect of changed bone matrix composition in metabolic bone disease on osteocyte mechanoresponsiveness.
\end{abstract}

Keywords Three-dimensional $\cdot$ Bone microdamage $\cdot$ Human cortical bone $\cdot$ Mechanical loading $\cdot$ Native matrix . Osteocytes

\section{Introduction}

Osteocytes are the most abundant cells in bone, comprising 90-95\% of all bone cells. However, their function is the least studied [1]. In bone, osteocytes are surrounded by a calcified collagenous matrix. They are connected with each other through their cell processes running through canaliculi that

Nathalie Bravenboer

n.bravenboer@amsterdamumc.nl

1 Department of Oral Cell Biology, Academic Centre for Dentistry Amsterdam (ACTA), University of Amsterdam and Vrije Universiteit Amsterdam, Amsterdam Movement Sciences, Amsterdam, The Netherlands

2 Department of Clinical Chemistry, Amsterdam University Medical Centers, Vrije Universiteit Amsterdam, Amsterdam Movement Sciences, P.O. Box 7057, 1007 MB Amsterdam, The Netherlands form an extensive canalicular network throughout the bone. As the principle mechanosensory bone cells, osteocytes play a pivotal role in the adaptation of bone to mechanical stimuli [2]. Mechanical loading causes deformation of bone, which creates a pressure gradient in the interstitial fluid present in the lacuno-canalicular network surrounding the osteocytes. This pressure gradient induces mechanical stimuli in the form of fluid shear stress [1]. Osteocytes sense this fluid shear stress by their processes and convert the mechanical stimuli into chemical signals such as nitric oxide (NO) and prostaglandin $\mathrm{E}_{2}$ [3]. Osteocytes orchestrate bone adaptation to mechanical loading by steering bone formation and/or bone resorption [3]. Mature osteocytes secrete sclerostin, a protein encoded by the SOST gene [4]. Sclerostin is a potent antagonist of Wnt signaling. It inhibits bone resorption by regulating osteoclastogenesis and promotes bone formation by regulating osteoblastogenesis [4-6]. Mechanical loading downregulates SOST expression, while disuse or a lack 
of loading causes an upregulation both in vivo and in vitro [7, 8]. Osteocytes induce osteoclastogenesis by increasing receptor activator of nuclear factor kappa-B ligand (RANKL) expression and by decreasing osteoprotegerin (OPG) expression, or conversely, the proportions can be reversed to inhibit bone resorption [9]. Moreover, osteocytes also function as endocrine cells to regulate phosphate homeostasis in the kidney by producing fibroblast growth factor 23 (FGF23) [9, 10]. FGF23 decreases 1,25-dihydroxyvitamin $\mathrm{D}_{3}\left(1,25(\mathrm{OH})_{2} \mathrm{D}_{3}\right)$ and parathyroid hormone $(\mathrm{PTH})$ concentrations to maintain blood phosphate and calcium levels, while the synthesis and secretion of FGF23 itself is regulated by $1,25(\mathrm{OH})_{2} \mathrm{D}_{3}$ and PTH $[11,12]$. Thus, osteocytes play a crucial role in bone homeostasis, as well as in the regulation of blood mineral and hormone levels. However, the mechanism of osteocyte regulation of bone remodeling in response to mechanical loading and phosphate homeostasis is still not fully understood.

Most studies use isolated primary osteocytes or osteocytelike cell lines such as MLO-Y4 cells in monolayer culture [13-16]. However, these models lack the 3D cell distribution that is highly important in determining the mechanoresponsiveness of osteocytes. OCY454 osteocyte-like cells cultured in $3 \mathrm{D}$ on a porous polystyrene scaffold exhibit increased SOST gene expression compared to monolayer culture [8]. A 3D model of human primary osteocytes seeded on biphasic calcium phosphate microbeads demonstrated that osteocytes in 3D culture express significantly more SOST and FGF23 than in 2D monolayer culture [5]. Human primary osteocytes in these 3D microbeads, but not in 2D monolayer, respond to PTH with decreased SOST gene expression and increased $R A N K L$ relative to $O P G$ gene expression [6]. These findings indicate that osteocytes in 3D better replicate the osteocyte phenotype in vivo and are therefore superior to 2D-cultured osteocytes $[5,6,8]$. It remains a challenge to isolate a sufficient number of primary osteocytes for cell culture experiments without losing the specific osteocyte characteristics, e.g., their mechanosensing capacity.

Osteocyte activity is affected by the calcified collagenous matrix in the native environment. Elevated extracellular calcium induces a rise of cytosolic calcium in chick osteocytes, affecting their activity [17]. Moreover, failure of type I collagen cleavage by collagenase results in osteocyte apoptosis [18]. Osteocyte activity is also affected by the oxygen concentration in the native matrix of osteocytes [19]. The prevailing oxygen concentration differs between osteocytes in cortical bone (4.2\%) and in monolayer culture $(18.6 \%)[20,21]$. Hypoxia $\left(1 \% \mathrm{O}_{2}\right)$ enhances mineralization and sclerostin protein expression of human primary osteocytes compared to normoxia $\left(20 \% \mathrm{O}_{2}\right)$, showing that hypoxia retains the osteocyte phenotype ex vivo [19]. Hormones, such as $1,25(\mathrm{OH})_{2} \mathrm{D}_{3}$, also affect osteocyte activity [22-25]. $1,25(\mathrm{OH})_{2} \mathrm{D}_{3}$ induces $C Y P 24 A 1$ [22] and $F G F 23$ expression
[23]. Increased $C Y P 24 A 1$ and $F G F 23$ expression result in decreased $1,25(\mathrm{OH})_{2} \mathrm{D}_{3}$ in a feedback loop to prevent excess vitamin $D$ pathway activation $[24,25]$. The native matrix of osteocytes contains cytokines such as interleukin- $1 \beta$, tumor necrosis factor- $\alpha$, and interleukin- 6 , that potentially affect osteocyte mechanoresponsiveness and signaling toward osteoclasts and/or osteoblasts [26-28]. Thus, the osteocyte microenvironment is important for their function and should be taken into account in studies on osteocyte mechanoresponsiveness. This also suggests that a model of osteocytes cultured in their native matrix is superior to a model of osteocytes cultured in 2D to mimic the in vivo osteocyte phenotype. Earlier we have shown that osteocytes cultured in their native matrix express sclerostin, and survive up to 7 days, thereby providing an in vitro platform to study osteocytes in their native matrix [29]. More knowledge regarding the effect of a changed matrix composition, as in metabolic bone disease, on osteocyte function might facilitate the development of new treatments for these diseases.

In this study, we cultured small human cortical bone explants obtained from iliac crest and fibula to study osteocytes in their native matrix. Mechanical loading was applied on bone explants using a custom-made loading apparatus [30]. In this 3D model, the osteocytes were maintained in their original environment, i.e., with their cell bodies in lacunae and their cell processes running through canaliculi, thereby connecting to other cells. Our aim was three-fold: 1) To validate whether the custom-made loading apparatus could reliably apply different magnitudes of loading on human cortical bone, 2) to study the viability and sclerostin expression of mechanically loaded human osteocytes, and 3 ) to investigate the effect of different loading magnitudes on bone microdamage. This model provides a 3D structure and a native microenvironment for osteocytes. It would be relevant to test whether a changed bone matrix, as in metabolic bone disease, affects osteocyte mechanosensitivity and/ or mechanoresponsiveness if our model appears suitable for studying osteocyte mechanoresponsiveness in healthy bone matrix.

\section{Materials and Methods}

\section{Human Cortical Bone Culture}

Bone explants were collected from 13 donors (age: 21-86). Donors presented no medical history of skeletal pathology or trauma. All bone explants were obtained with donor's consent, and all protocols were approved by the local Medical Ethical Committee of the Amsterdam University Medical Centers (2016.105). Bone from the iliac crest was collected during maxillary sinus floor elevation surgery, and fibular bone was collected during mandible reconstruction surgery. 
Cortical iliac crest and fibular bone explants were washed in Hanks' balanced salt solution (HBSS; Thermo Fisher Scientific, Waltham, MA, USA), incubated in $2 \mathrm{mg} / \mathrm{ml}$ type II collagenase (Worthington Biochemical, Lakewood, CA, USA) in minimal essential medium (MEM; Thermo Fisher Scientific) for $2 \mathrm{~h}$ in a shaking waterbath at $37^{\circ} \mathrm{C}$. Cortical bone explants were washed again twice with HBSS, and soft tissue and trabecular bone were removed. Cleaned cortical bone was cut into small explants measuring $8.0 \times 3.0 \times 1.5 \mathrm{~mm}$ $(1 \times w \times h)$ using a diamond disc H-345-220 (Horico, Berlin, Germany), a handpiece (KaVo, Biberach an der Riss, Germany), and a foot control (KaVo). Explants were cooled in ice-cold HBSS during cutting. They were pre-cultured for 1 or 2 days in 6-well plates (Merck KGaA, Darmstadt, Germany), containing MEM supplemented with 5\% fetal bovine serum (FBS; Lonza BioWhittaker, Basel, Switzerland), 5\% bovine calf serum (BCS; Thermo Fisher Scientific), $1 \%$ penicillin-streptomycin $(10,000 \mathrm{U} / \mathrm{mL}$; Thermo Fisher Scientific), and 0.5\% amphotericin B solution (Merck $\mathrm{KGaA}$ ) at $37^{\circ} \mathrm{C}$.

\section{Mechanical Loading}

Explants were mechanically loaded by three-point bending with a custom-made loading apparatus, which generated sinusoidal displacement using a computer-driven voice coil linear microactuator (type NCM04-25-250-2LVE; H2W Technologies, Valencia, CA, USA) as described earlier [30-32]. Explants were placed in a chamber $(6.0 \times 5.5 \times 5 \mathrm{~cm} ; 1 \times \mathrm{w} \times \mathrm{h})$ supplemented with MEM containing 5\% FBS, $5 \%$ BCS, $1 \%$ penicillin-streptomycin, and $0.5 \%$ amphotericin B solution. The two ends of an explant were placed on a custom-made bone holder. The indenter for displacement application was positioned in the center of the explant. The force exerted on the explant and the displacement were monitored and registered simultaneously [31]. The force and displacement data were recorded by a custom-made algorithm (implemented in LabVIEW 8.2, National Instruments, Austin, TX, USA) [30]. Application of mechanical loading resulted in defined bone deformation or microstrain $(\mu \varepsilon)$. The displacement of the micro-actuator was calculated by the following formula [33]: loading magnitudes (range: $2302-13,811 \mu \varepsilon$ ) to assess the relationship between loading magnitude and force. To ensure contact between explant and indenter, a pre-load of 0.5 or $1 \mathrm{~N}$ was applied prior to mechanical loading to ensure contact between explant and indenter [30]. Thereafter, explants were subjected to a $5 \mathrm{~min}$ bending at different magnitudes (range: $2302-13,811 \mu \varepsilon$ ) and at different frequencies $(1,1.5$, 2 , and $5 \mathrm{~Hz}$ ). To determine a suitable regime to keep the contact between explant and indenter, two pre-loads $(0.5$ and $1 \mathrm{~N})$ and four different loading frequencies $(1,1.5,2$, and $5 \mathrm{~Hz}$ ) were tested. Contact preservation at different frequencies and different pre-load magnitudes was determined by calculating the percentage of the force at the end of the mechanical loading to the initial pre-load force applied. The displacement preservation at different frequencies was expressed as the percentage of the displacement at half duration of the mechanical loading to the initial displacement. Immediately after mechanical loading, explants were either or not post-cultured for $24 \mathrm{~h}$ in MEM containing 5\% FBS, $5 \%$ BCS, $1 \%$ penicillin-streptomycin, and $0.5 \%$ amphotericin B solution.

\section{Cell Viability}

Explants were collected at day -2 (pre-culture), day 0 (preload), day 1 (without loading at $24 \mathrm{~h}$ post-culture), and day 1 (with $1600 \mu \varepsilon$ loading for $5 \mathrm{~min}$ at $1 \mathrm{~Hz}$ at $24 \mathrm{~h}$ postculture). Explants were incubated with freshly prepared lactate dehydrogenase (LDH) solution containing 5\% polypep (Merck KGaA), 2 mM Gly-Gly (Merck KGaA), $0.75 \% \mathrm{NaCl}$ (Thermo Fisher Scientific), $60 \mathrm{mM}$ lactic acid (Merck KGaA), 1.75 mg/mL B-nicotinamide adenine (Merck $\mathrm{KGaA}$ ), and $30 \mathrm{mg}$ nitro blue tetrazolium (Merck KGaA), $\mathrm{pH} 8.0$, for $24 \mathrm{~h}$ in a shaking water bath at $37^{\circ} \mathrm{C}$. Then, explants were washed twice with phosphate-buffered saline (PBS) and fixated in $4 \%$ paraformaldehyde for $24 \mathrm{~h}$ at $4{ }^{\circ} \mathrm{C}$ [34]. Fixated explants were washed twice with PBS, dehydrated in graded ethanol series, and embedded in methylmethacrylate (MMA; BDH Chemicals, Poole, UK). Five $\mu \mathrm{m}$ thick sections were cut using a Polycut S (SM2500) microtome (Leica/Reichert-Jung, Nussloch, Germany). Sections were mounted in depex (Avantor, Radnor, PA,

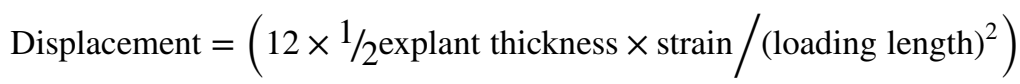

where the loading length is the length of the loaded part of the explant, which was calculated as the distance between two holding points of the explant. The thickness of the explant was calculated as the mean of the thickness of the two ends and the thickness at the center of the explant using a calibrator (Nakamura Mfg, Tokyo, Japan). Different displacements were applied on explants representing different
USA) and covered by cover slips. Digital images of LDHstained explants were captured with a microscope (Eclipse 80i; Nikon, Tokyo, Japan), equipped with a DS-Fil camera (Nikon) and NIS-Elements AR software (version 4.13, Nikon). For each section, one focused image was generated from 15 to 31 images captured at 3 or $5 \mu \mathrm{m}$ Z-intervals with a $20 \times / 0.5$ NA objective (CFI Plan Fluor, Nikon). Blue 
LDH-stained viable osteocytes and empty osteocyte lacunae were counted at $\times 200$ magnification. The percentage of viable osteocytes was calculated in relation to the total number of osteocytes (i.e., total number of empty and osteocyte-filled lacunae).

\section{Sclerostin Immunostaining}

Explants collected at day -1/-2 (pre-culture), day 0 (preloading), day 1 (without loading at $24 \mathrm{~h}$ post-culture), and day 1 (loaded by 2000 or $8000 \mu \varepsilon$ for $5 \mathrm{~min}$ at $1 \mathrm{~Hz}$, at $24 \mathrm{~h}$ postculture) were embedded in MMA and cut into $5 \mu \mathrm{m}$ thick sections as described under "cell viability." These sections were rehydrated, and endogenous peroxidase was quenched with $3 \% \mathrm{H}_{2} \mathrm{O}_{2}$ in a mixture of $40 \%$ methanol in PBS. Antigen retrieval was performed by incubation with proteinase $\mathrm{K}$ for $15 \mathrm{~min}$ at $37^{\circ} \mathrm{C}$. The sections were incubated with 1/100 mouse-anti-sclerostin antibody, RRID:AB_2195349 (Bio-Techne, Minneapolis, MN, USA) for $3 \mathrm{~h}$ at room temperature, followed by incubation with Envision mousespecific antibody (Agilent, Santa Clara, CA, USA) for $30 \mathrm{~min}$. For color development, sections were incubated with DAB-Nickel substrate and counterstained with Nuclear fast red. Sclerostin staining was visualized using a microscope (Eclipse 80i; Nikon), equipped with a DS-Fi1 camera (Nikon) and NIS-Elements AR software (version 4.13, Nikon). For each section, one focused image was generated from 19 to 25 images captured at $3 \mu \mathrm{m}$ or $5 \mu \mathrm{m}$ Z-intervals with a $20 \times / 0.5$ NA objective (CFI Plan Fluor, Nikon). The number of sclerostin-positive osteocytes and the total number of osteocyte lacunae were counted in three areas of interest of the same size $\left(2.94\right.$ or $\left.2.16 \mathrm{~mm}^{2}\right)$ in each section: two areas of interest were located at the two ends of the section, and one area of interest was located in the center of the section.

\section{Real-time PCR}

Cortical explants cultured for 7 days were treated without or with $10^{-7} \mathrm{M} 1,25(\mathrm{OH})_{2} \mathrm{D}_{3}$ for $24 \mathrm{~h}$. TRIzol® Reagent (Thermo Fisher Scientific) was added for $30 \mathrm{~min}$. Total RNA was isolated from osteocytes according to the manufacturer's protocol (Thermo Fischer Scientific). The RNA concentration was determined using a Nanodrop spectrophotometer (Nanodrop Technologies, Wilmington, DE, USA). RNA was reverse transcribed from $100 \mathrm{ng}$ total RNA in a $20 \mu \mathrm{L}$ reaction mixture as described [35]. The PCR reaction was performed on $25 \mu \mathrm{L}$ reaction mixture containing $3 \mu \mathrm{L}$ cDNA, $300 \mathrm{nmol} / \mathrm{L}$ forward and reverse primer and $\mathrm{iQ}^{\mathrm{TM}} \mathrm{SYBR}$ Green Supermix (Bio-Rad, Hercules, CA, USA). The following primer sets were used: CYP24A1, forward: 5'-CAA ACCGTGAAGGCCTATC-3' reverse: 5'-AGTCTTCCCCTT CCAGGATCA-3'; FGF23, forward: 5'-TGAGCGTCCTCA
GAGCCTAT-3', reverse: 5'-TTGTGGATCTGCAGGTGG TA-3'; GALNT3, forward: 5'-AGGAACGTGGGGAAGCTA AA-3', reverse: 5'-GTCGAGTGTCTGGTCCAAGA-3'; PHEX, forward: 5'-CCGAAGCCATACAGAAAGCCT-3', reverse: 5'-CGGAAAGGTGAATGCCGTAG-3'; RANKL, forward: 5'-CGGGGTGACCTTATGAGAAA-3', reverse: 5'-GCGCTAGATGACACCCTCTC-3'; SOST, forward: 5'-ACCACCCCTTTGAGACCAAAG-3', reverse: 5'-GGT CACGTAGCGGGTGAAGT-3'. PCR was performed on an iCycler $\mathrm{iQ}^{\mathrm{TM}}$ RealTime PCR Detection System (Bio-Rad): $3 \mathrm{~min}$ at $95^{\circ} \mathrm{C}, 40$ cycles consisting of $15 \mathrm{~s}$ at $95^{\circ} \mathrm{C}$ and $1 \mathrm{~min}$ at $60^{\circ} \mathrm{C}$. Relative gene expression was calculated by the $2^{\Delta \mathrm{Ct}}$ method. TATA binding protein $(T B P)$ gene was used as a housekeeping gene (sequence, forward: $5^{\prime}$-AGT TCTGGGATTGTACCGCA-3', reverse: 5'-TCCTCATGA TTACCGCAGCA-3').

\section{Micro-computed Tomography Analysis}

Explants were cut as described under "mechanical loading" and kept in 12-wells plates (Corning, New York, NY, USA) in water at $4{ }^{\circ} \mathrm{C}$. Explants were scanned by micro-CT (Scanco Medical A.G., model $\mu$ ct40, Basel, Switzerland). The tube voltage of the micro-CT scanner was $70 \mathrm{kVp}$, and the tube current of $0.114 \mathrm{~mA}$. The scanning resolution was 18 micron. Explant images were reconstructed by measuring the radiolucency of the object with sensors and rotating $\mathrm{X}$-ray beams from different angles and subsequent calculation of the 3D structure. Bone volume (BV) was determined using the standard method of the micro-CT evaluation program [36]. The threshold was $560 \mathrm{mg}$ hydroxyapatite (HA)/ $\mathrm{cm}^{3}$, indicating that every voxel with a bone density value above $560 \mathrm{mg} \mathrm{HA} / \mathrm{cm}^{3}$ was defined as bone.

\section{Quantification of Microdamage}

Barium sulfate $\left(\mathrm{BaSO}_{4}\right)$ staining was used as a contrast enhancer for microdamage detection in explants as described [37]. $\mathrm{BaSO}_{4}$ precipitates in microcracks, resulting in a high density on micro-CT scans. The explants were soaked in a solution of equal parts $0.9 \% \mathrm{NaCl}$, acetone (Avantor), and $0.5 \mathrm{M} \mathrm{BaCl}_{2}$ (Merck KGaA) in demineralized water for 3 days. Then, the explants were washed in demineralized water to remove excess ions and particles from the explant surface. Then, the explants were soaked in a solution of equal parts $0.9 \% \mathrm{NaCl}$, acetone, $0.5 \mathrm{M} \mathrm{Na}_{2} \mathrm{SO}_{4}$ (Merck $\mathrm{KGaA}$ ) in demineralized water for 3 days, washed with demineralized water, and scanned by micro-CT. Explants were kept under vacuum ( $900 \mathrm{mBar}$ ) during the 6 days of preparation. All solutions were neutralized to $\mathrm{pH} 7.0$ before use.

Explants were scanned 3 times, i.e., before loading, after loading $(500,1500,2500,4500,6500$, and $7500 \mu \varepsilon$ at $1 \mathrm{~Hz}$ with a pre-load of $0.95-1.05 \mathrm{~N}$ for $5 \mathrm{~min}$ ), and 
after loading without/with $\mathrm{BaSO}_{4}$ staining. Explants were scanned perpendicular to the longitudinal axis. The bone mineral density (BMD) of 3 scans was used to quantify the microdamage caused by loading. The micro-CT scans of unloaded, loaded, and $\mathrm{BaSO}_{4}$-stained loaded explants were transformed to the same position using a custom-made 3D rigid registration program (Academic Center for Dentistry Amsterdam (ACTA), Amsterdam, The Netherlands). The micro-CT scans of unloaded explants were used as the destination position for the micro-CT scans of mechanically loaded $\mathrm{BaSO}_{4}$-stained explants. A voxel mask was produced consisting of all overlapping voxels in the 3 micro-CT scans that had been rotated to the same position. To prepare a BMD graph, a mask was applied to the 3 micro-CT scans to remove ill-defined staining values. Five surface layers were deleted to remove precipitated $\mathrm{BaSO}_{4}$ on the free surface of the explants, which did not represent microcracks. The BMD of the unloaded micro-CT scan was subtracted from that of the mechanically loaded $\mathrm{BaSO}_{4}$-stained micro-CT scan, which was used to calculate the difference in BMD between the two scans. The difference in BMD was at the most 300 native units. Therefore, all voxels with a value above 300 native units were considered as $\mathrm{BaSO}_{4}$-stained volume (SV).
The ratio of $\mathrm{BaSO}_{4}$-stained volume and bone volume (SV/ $\mathrm{BV}$ ) was determined as microdamage in explants. 3D images of $\mathrm{BaSO}_{4}$-stained volume in explants were made with paraview program (para-view version 5.6, Kitware Inc., New York, NY, USA).

\section{Statistical Analysis}

Linear regression analysis was used to determine the relationship between displacement and force, as well as between microstrain and force. Unpaired t-test was used to compare the contact preservation during loading with different preloads and the displacement preservation during loading at different frequencies. One-way ANOVA test and unpaired t-test were used to compare the percentage of sclerostin-positive osteocytes in different groups. Paired $t$-test was used to compare differences in gene expression between control and $1,25(\mathrm{OH})_{2} \mathrm{D}_{3}$-treated bone. One-way ANOVA and unpaired $t$-test were used to compare differences in SV/BV between explants loaded at different magnitudes. All analyses were performed using GraphPad Prism software 9 (GraphPad, San Diego, CA, USA). A p-value $<0.05$ was considered significant (Figs. 1, 2).

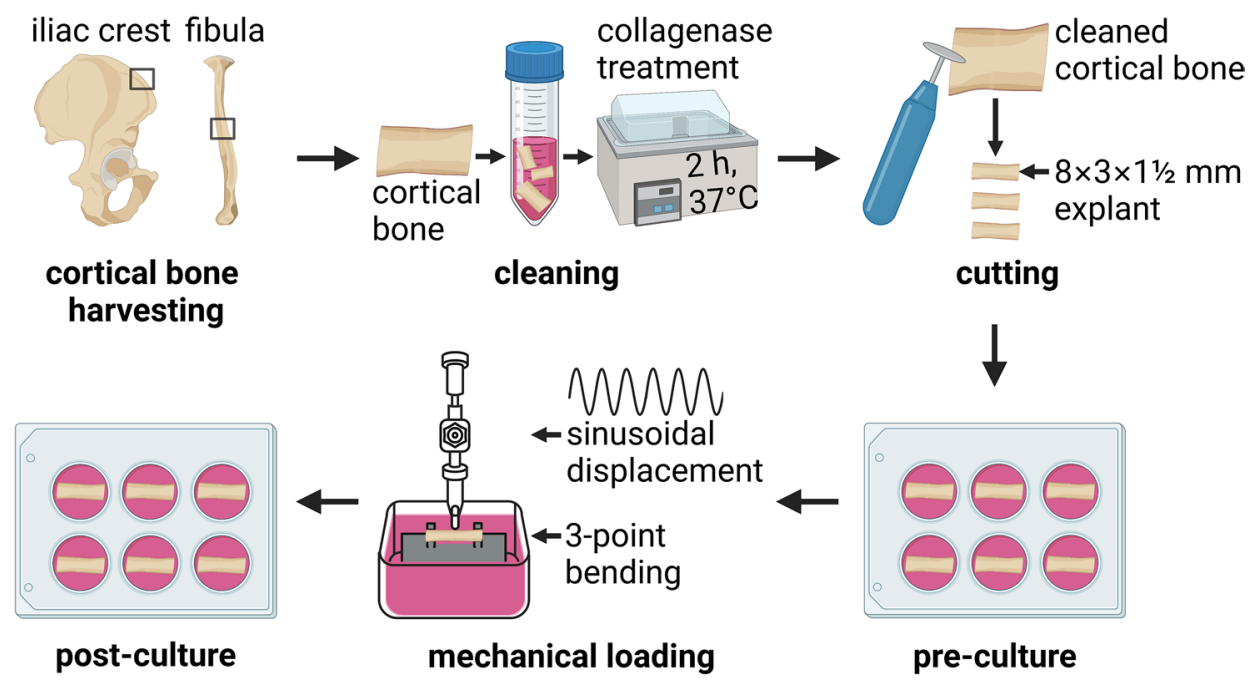

Fig. 1 Schematic overview of human cortical bone explants preparation, mechanical loading using the custom-made loading apparatus, and culture. Cortical iliac crest bone was harvested during maxillary sinus floor elevation surgery, and fibular bone was harvested during mandible reconstruction surgery (indicated by squares). Cortical iliac crest bone and fibular bone were incubated in $2 \mathrm{mg} / \mathrm{ml}$ type II collagenase in MEM for $2 \mathrm{~h}$ in a shaking waterbath at $37^{\circ} \mathrm{C}$. Cleaned cortical bone was cut into small explants measuring $8.0 \times 3.0 \times 1.5 \mathrm{~mm}$ $(1 \times w \times h)$ using a diamond disc and a handpiece. Explants were precultured in 6-well plates with MEM supplemented with 5\% FBS, $5 \%$ BCS, $1 \%$ penicillin-streptomycin, and $0.5 \%$ amphotericin B solution at $37{ }^{\circ} \mathrm{C}$. Explants were mechanically loaded for $5 \mathrm{~min}$ by three-point bending with a custom-made loading apparatus, which generated sinusoidal displacement. During loading, explants were placed in a chamber $(6.0 \times 5.5 \times 5 \mathrm{~cm} ; 1 \times \mathrm{w} \times \mathrm{h})$ supplemented with MEM plus additives. The two ends of an explant were placed on a custom-made bone holder. The indenter for displacement application was positioned in the center of the explant. The displacement of the micro-actuator was calculated by the formula Displacement $=(12 \times 1 / 2$ explant thickness $\times$ strain/(loading length $\left.)^{2}\right)$. Immediately after mechanical loading, explants were either or not post-cultured for $24 \mathrm{~h}$ in MEM plus additives. Figure created with BioRender.com 
Fig. 2 Images of human cortical bone explants during preparation, mechanical loading using the custom-made loading apparatus, and culture. Cortical iliac crest was harvested during maxillary sinus floor elevation surgery, and fibular bone was harvested during mandible reconstruction surgery. Cortical bone was cleaned and cut into small explants measuring $8.0 \times 3.0 \times 1.5 \mathrm{~mm}(1 \times \mathrm{w} \times \mathrm{h})$. After pre-culture for 1 or 2 days, explants were mechanically loaded for $5 \mathrm{~min}$. Immediately thereafter, mechanically loaded explants were either or not postcultured for $24 \mathrm{~h}$. Figure created with BioRender.com

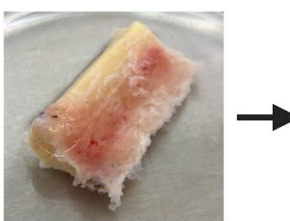

harvested cortical bone

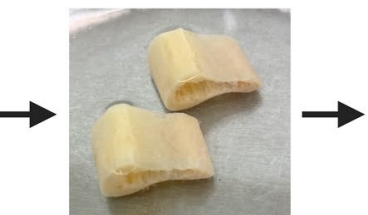

cleaned and cut cortical bone

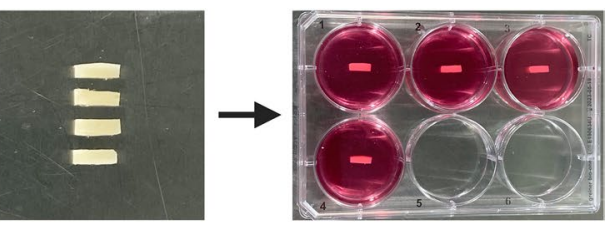

explants

pre-culture

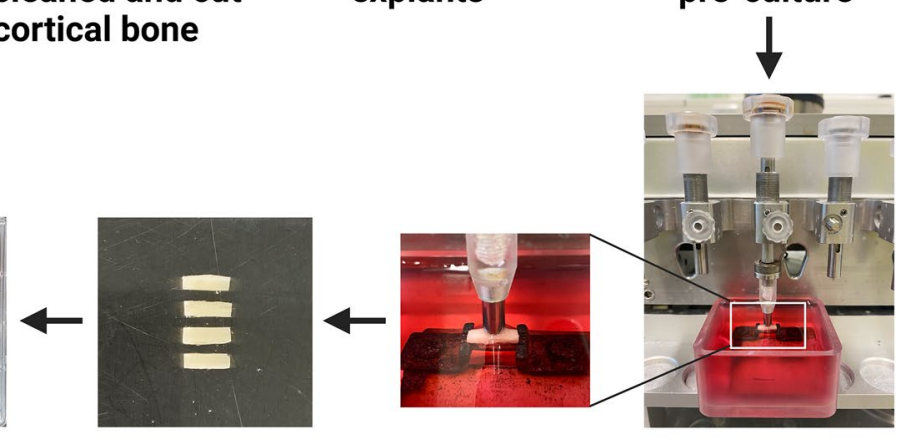

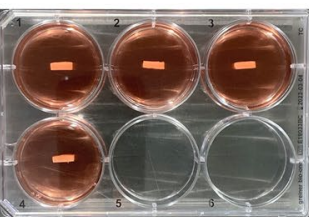

post-culture mechanical loading mechanical loading

\section{Results}

\section{Mechanical Loading of Human Cortical Bone Using a Custom-Made Loading Apparatus}

To determine whether it is possible to reliably apply a defined magnitude of loading on human cortical bone explants by three-point bending using the custom-made loading apparatus, we assessed the relationship between the applied displacement or magnitude and force. Sinusoidal displacement and force on explants were recorded simultaneously during loading (Fig. 3a). There was a significant positive linear relation between the displacement or microstrain and the force in 3 explants ( $p<0.05$; Fig. 3b, c). When the explants were loaded by the same displacement $(50,100$, $150,200 \mu \mathrm{m})$, the force exerted on the 3 explants was similar, demonstrating that the custom-made loading apparatus did reliably apply mechanical loading on different explants (Fig. 3b).

Contact preservation between the explant and the indenter during loading is essential for reliably applying mechanical loading on the explant. Pre-loads and frequencies of different magnitudes were applied to investigate whether this would affect the contact between explant and indenter during loading. A pre-load of $1 \mathrm{~N}$ followed by loading slightly, but not significantly, improved contact preservation compared to a pre-load of $0.5 \mathrm{~N}$ (Fig. 3d). Therefore, a pre-load of $1 \mathrm{~N}$ was chosen for further experimentation. When explants were loaded at a frequency of 1, 1.5, 2, or $5 \mathrm{~Hz}$, the contact between explant and indenter was preserved during loading (Fig. 3e). To test whether the loading frequency affected the displacement of the indenter, explants were loaded at 1 or $2 \mathrm{~Hz}$. Loading at $1 \mathrm{~Hz}$ showed improved displacement preservation compared to loading at $2 \mathrm{~Hz}$ ( $p<0.05$; Fig. 3f). Therefore, a loading frequency of $1 \mathrm{~Hz}$ was chosen for further experimentation.

\section{Cell Viability of Mechanically Loaded Osteocytes in Their Native Matrix}

The viability of osteocytes before and after mechanical loading was tested (Fig. 4a). The percentage of viable osteocytes was similar in all groups, i.e., $84 \%$ in pre-culture explants (day -2), $74 \%$ in pre-loading explants (day 0 ), $79 \%$ in explants without loading (day 1), and $76 \%$ in explants with $1600 \mu \varepsilon$ loading at $24 \mathrm{~h}$ post-culture (day 1; Fig. $4 \mathrm{~b}$ ). Thus, loading at $1600 \mu \varepsilon$ did not affect osteocyte viability at $24 \mathrm{~h}$ post-culture.

\section{Sclerostin Expression by Mechanically Loaded Osteocytes in Their Native Matrix}

The phenotypic stability of mechanically loaded osteocytes was investigated by measuring sclerostin protein expression. The number of sclerostin-positive stained osteocytes and the total number of osteocytes were counted at $24 \mathrm{~h}$ post-culture (Fig. 5a). The percentage of sclerostin-positive osteocytes was similar in all groups, i.e., $13 \%$ in pre-culture explants (day -1/-2), 7\% in explants without loading (day 1), $16 \%$ in $2000 \mu \varepsilon$ loaded explants, and $29 \%$ in $8000 \mu \varepsilon$ loaded explants (day 1; Fig. 5d).

\section{$1,25(\mathrm{OH})_{2} \mathrm{D}_{3}$ Stimulation of Osteocytes in Their Native Matrix}

To study whether osteocytes in our mechanical loading model keep their phenotype and respond to $1,25(\mathrm{OH})_{2} \mathrm{D}_{3}$, 
Fig. 3 Application of defined mechanical loading on human cortical bone explants using a custom-made loading apparatus. a Sinusoidal displacement of indenter and force exerted on explants were monitored and registered simultaneously. b Dose-response relationship between indenter displacement and force on 3 separate explants (bone 1, 2, 3) obtained from 2 different patients. $\mathbf{c}$ Doseresponse relationship between loading magnitude and force on 3 separate explants (bone 1, 2, 3) obtained from 2 different patients. d Contact preservation between explant and indenter with different pre-load. Contact preservation was expressed as percentage of force at the end of loading to the initial pre-load applied $(n=6)$. e Contact preservation between explant and indenter at different mechanical loading frequencies $(n=3)$. $\mathbf{f}$ Displacement preservation at mechanical loading frequencies of 1 and $2 \mathrm{~Hz}$. Displacement preservation was expressed as percentage of displacement at half duration of loading to the initial displacement $(n=7)$. Values are mean \pm SD. $*$ Significantly different from $1 \mathrm{~Hz}$, $p<0.01$
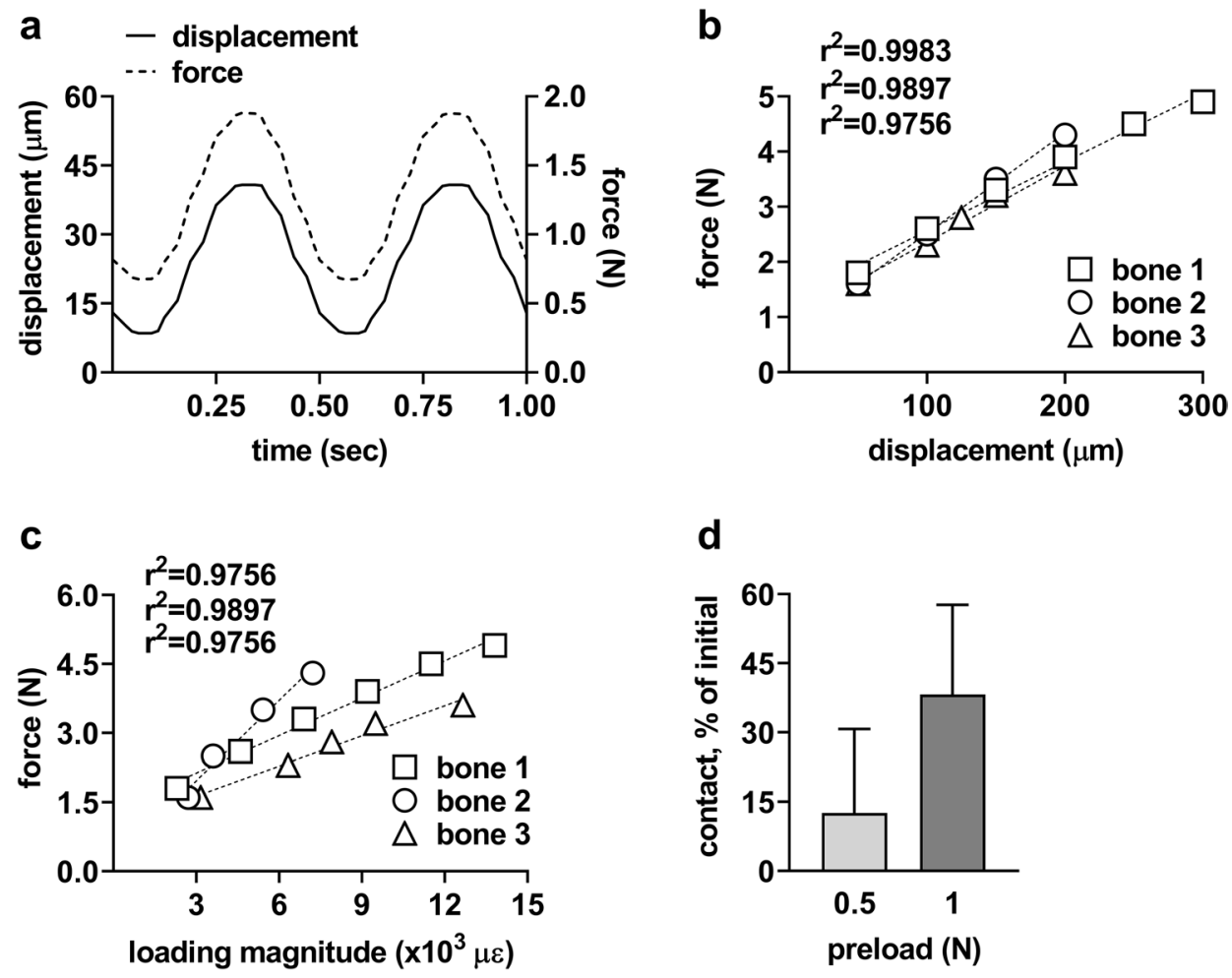

d
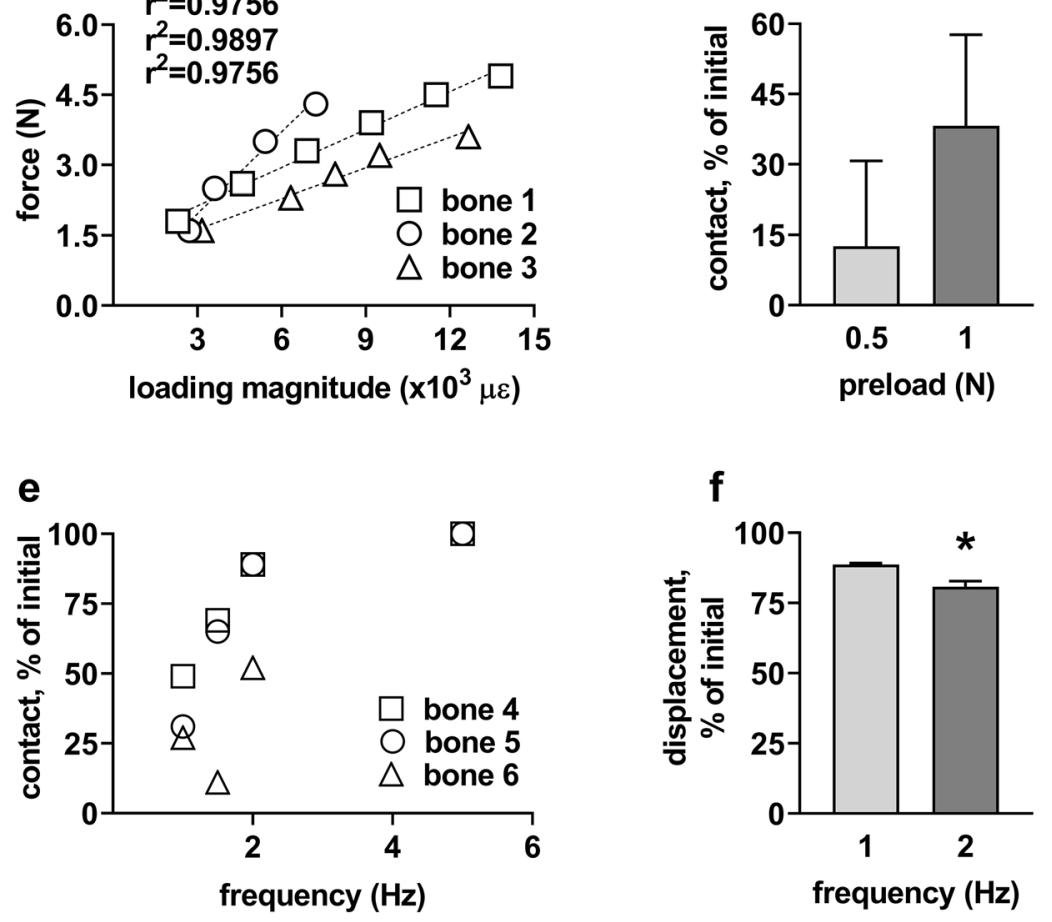

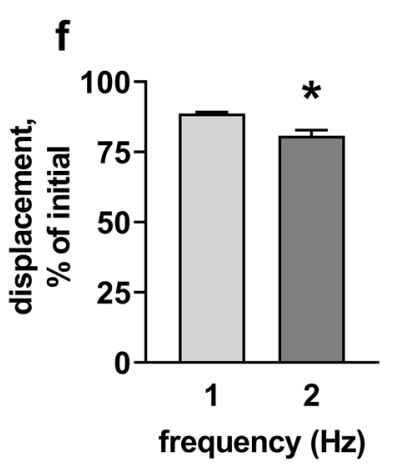

we tested the effect of $10^{-7} \mathrm{M} 1,25(\mathrm{OH})_{2} \mathrm{D}_{3}$ on $C Y P 24 A 1$, FGF23, GALNT3, PHEX, RANKL, and SOST gene expression. $1,25(\mathrm{OH})_{2} \mathrm{D}_{3}$ treatment significantly increased CYP24A1 expression ( $p<0.05$, Fig. 6a), indicating that osteocytes sensed and responded to $10^{-7} \mathrm{M} 1,25(\mathrm{OH})_{2} \mathrm{D}_{3}$. $1,25(\mathrm{OH})_{2} \mathrm{D}_{3}$ treatment did not affect $F G F 23$ gene expression (Fig. 6b), but significantly decreased GALNT3 gene expression ( $p<0.05$, Fig. 6c). PHEX, RANKL, and SOST gene expression were not affected by $1,25(\mathrm{OH})_{2} \mathrm{D}_{3}$ (Fig. 6d-f). The fact that osteocytes expressed osteocytespecific markers FGF23 and SOST demonstrated that the osteocytes maintained their osteocytic phenotype in our mechanical loading model.

\section{Mechanical Loading at Different Magnitudes and Explant Microdamage}

To investigate whether loading at different magnitudes causes explant microdamage, $\mathrm{BaSO} 4$ staining was performed to indicate and quantify microdamage. Explants were either unloaded or loaded at $500 \mu \varepsilon$ to $7500 \mu \varepsilon$. 3D images of mechanically loaded explants revealed the location of $\mathrm{BaSO}_{4}$-stained bone indicating microdamage (Fig. 7a). The amount of microdamage was similar in unloaded and loaded explants (Fig. 7b). This indicated that mechanical loading up to $7500 \mu \varepsilon$ did not increase microdamage compared to unloaded explants. 
Fig. 4 Mechanical loading did not affect osteocyte viability $24 \mathrm{~h}$ after loading. a Microphotographs showing LDHpositive osteocytes (blue) in human cortical bone explants. Black arrows: LDH-positive osteocytes in their lacunae; scale bar: $50 \mu \mathrm{m}$. b Quantification of osteocyte viability. Values are mean percentage of LDH-positive osteocytes to total osteocytes, in explants from 2 donors. Ocy, osteocytes; LDH, lactate dehydrogenase

a

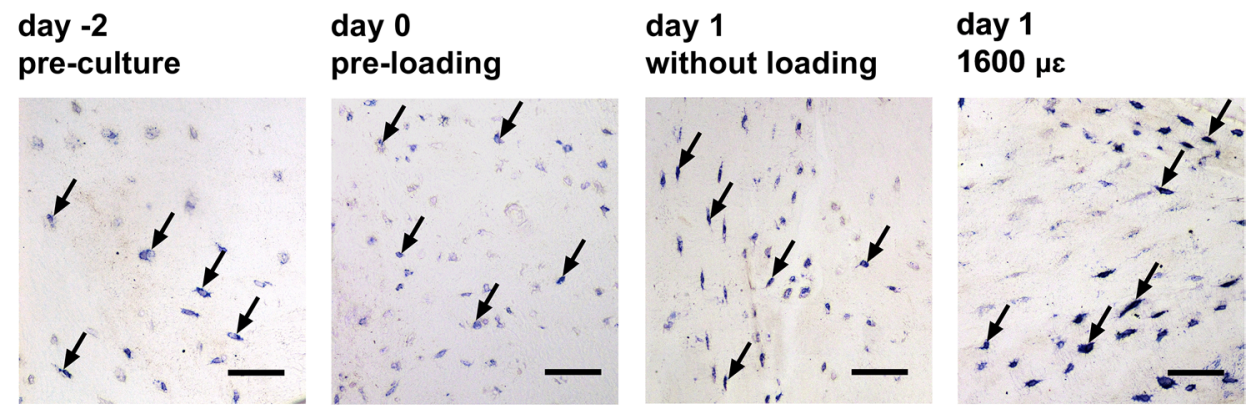

b

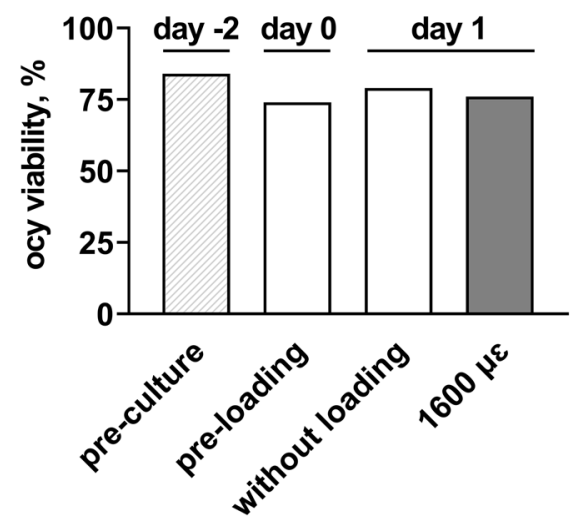

a

\section{day $-1 /-2$ \\ pre-culture}

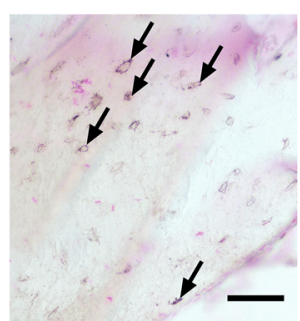

b

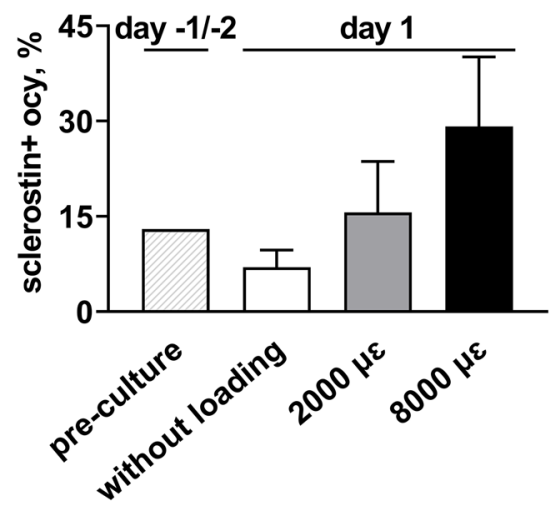

without loading

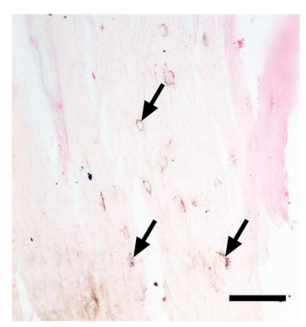

day 1

$2000 \mu \varepsilon$

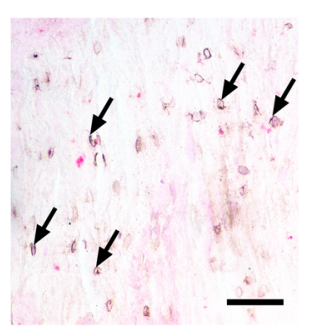

day 1

$8000 \mu \varepsilon$

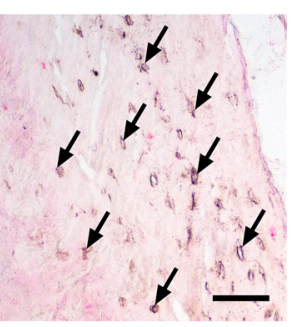

sclerostin-positive osteocytes

scale bar: $50 \mu \mathrm{m}$. b Percentage

of sclerostin-positive osteocytes

to total osteocytes. There was

no significance between groups, $\mathrm{p}>0.05$. Values are mean $\pm S D$ of data from 1 donor. Sclerostin + ocy, sclerostin-positive osteocytes 
Fig. 6 One day $1,25(\mathrm{OH})_{2} \mathrm{D}_{3}$ $\left(10^{-7} \mathrm{M}\right)$ treatment increased CYP24A1 expression, decreased GALNT3 expression, but did not affect $F G F 23, P H E X, R A N K L$, and SOST gene expression in osteocytes in their native matrix of human cortical bone after 1 week of culture. Osteocytic gene expression of: a $C Y P 24 A 1$, b FGF23, c GALNT3, d PHEX, e $R A N K L, \mathbf{f} S O S T$. Values are mean \pm SD of data from 5 donors. *Significant effect of $1,25(\mathrm{OH})_{2} \mathrm{D}_{3}, \mathrm{p}<0.05$. Con, control; $1,25 \mathrm{D}, 1,25(\mathrm{OH})_{2} \mathrm{D}_{3}$
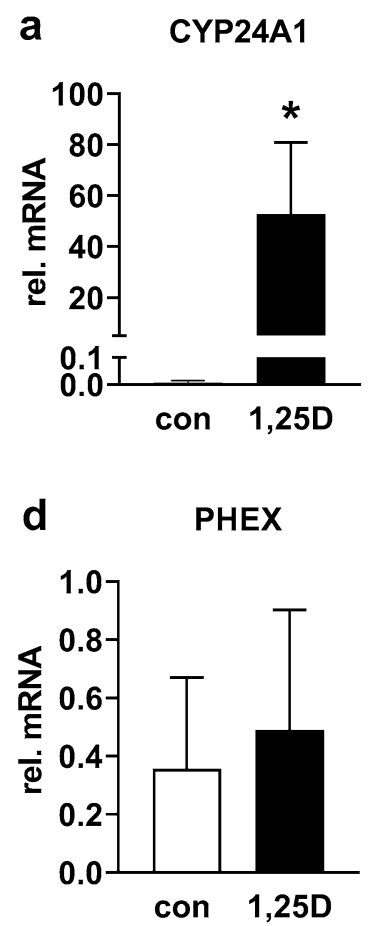
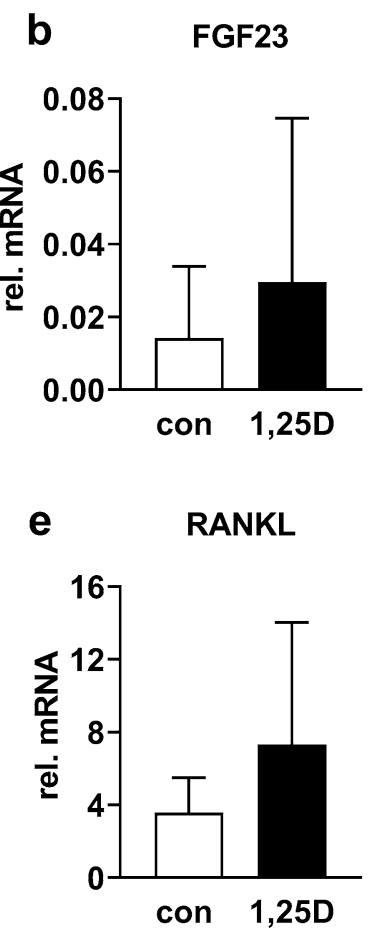

C

GALNT3
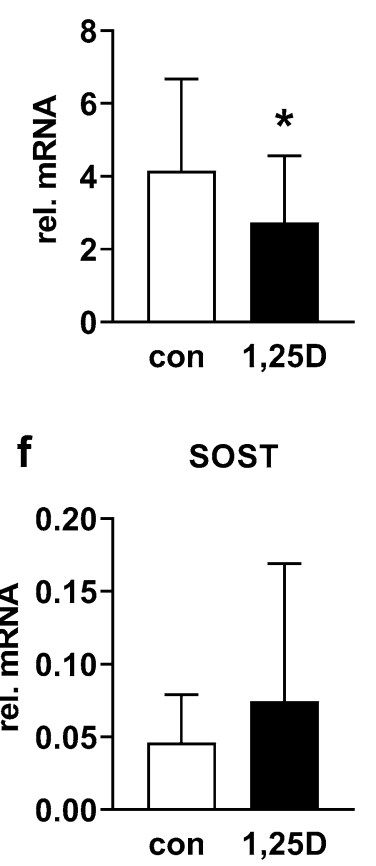

\section{Discussion}

\section{a}
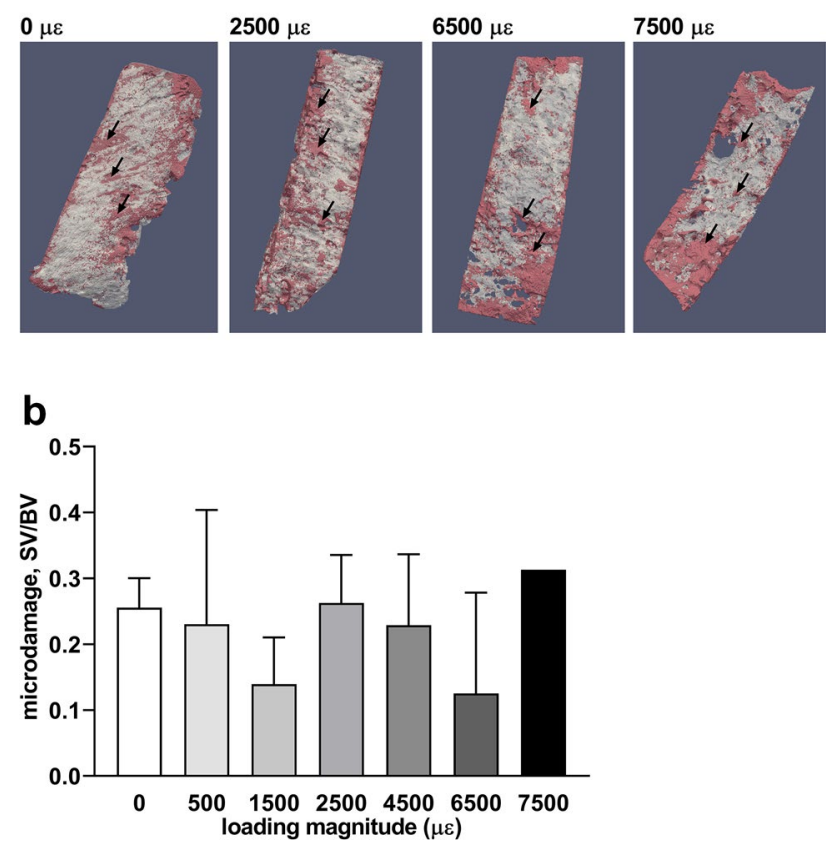

Fig. 7 Mechanical loading up to $7500 \mu \varepsilon$ did not increase microdamage in bone. a $3 \mathrm{D}$ images of unloaded explants $(0 \mu \varepsilon)$, and explants loaded at 2500, 6500, and $7500 \mu \varepsilon$ at $1 \mathrm{~Hz}$ for $5 \mathrm{~min}$. Red area: $\mathrm{BaSO}_{4}$-stained microdamage (black arrows). Gray area: not-damaged bone. b Microdamage determined as $\mathrm{BaSO}_{4}$-stained volume/ bone volume $(\mathrm{SV} / \mathrm{BV})$ of unloaded $(0 \mu \varepsilon)$ and loaded explants $(500$, $1500,2500,4500,6500,7500 \mu \varepsilon)$. There was no significant difference between different loading magnitudes. Values are mean \pm SD of data from 3 donors
In this study, a 3D mechanical loading model of human osteocytes in their native matrix was developed and validated. Using our custom-made loading apparatus, a dose-response relationship between displacement and force and between magnitude and force was observed. The osteocytes in bone exposed to mechanical loading of 1600-8000 $\mu \varepsilon$ were highly viable at $24 \mathrm{~h}$ post-culture. The osteocytes in this model maintained their osteocytic phenotype, as shown by sclerostin expression, as well as by gene expression of osteocytespecific markers FGF23 and SOST. Mechanical loading up to $7500 \mu \varepsilon$ did not increase explant microdamage. These findings indicate that our 3D mechanical loading model is suitable for investigating the mechanosensitivity and mechanoresponsiveness of human osteocytes in their native matrix.

Our 3D mechanical loading model used a custommade loading apparatus to apply a well-defined magnitude of mechanical loading on human cortical bone. The observed linear relationship between the loading magnitude (2302-13,811 $\mu \varepsilon)$ and force on explants from two donors indicated that this model allows application of different loading magnitudes on explants from different donors. This agrees with published data also showing a dose-response relationship between force and microstrain in mouse ulna bone [38]. Moreover, we compared the effect of pre-load $(0.5$ or $1 \mathrm{~N})$ on contact preservation since preliminary data showed that the contact between explant and indenter was not preserved during the loading session, due possibly to a change in bone shape during loading. If the contact is not 
preserved, the displacement of the indenter applied on the explant will decrease, resulting in unreliable strain calculations. We found that $1 \mathrm{~N}$ pre-load followed by mechanical loading promoted contact preservation compared to $0.5 \mathrm{~N}$ pre-load. Moreover, it has been reported that mechanical loading at $1 \mathrm{~N}$ generates little bone formation [38]. Therefore, to maintain contact between explant and indenter, and to minimize the effect of pre-load on osteocyte mechanoresponsiveness, we choose for a $1 \mathrm{~N}$ pre-load. We also tested whether the contact between explant and indenter was affected by frequency. All contact was preserved between explant and indenter at frequencies of $1,1.5,2$, and $5 \mathrm{~Hz}$.

The frequency of mechanical loading did not only affect the contact preservation between explant and indenter, but also the accuracy of indenter displacement. We found that mechanical loading at $1 \mathrm{~Hz}$ improved displacement preservation compared to loading at $2 \mathrm{~Hz}$. These frequencies were chosen based on published data showing that most strain energy in walking dogs is contained between 0 and $2 \mathrm{~Hz}$ [39]. Moreover, loading at 1610, 2640, 3660, and 4680 $\mu \varepsilon$ at $1 \mathrm{~Hz}$ induces rat ulna cortical bone formation in a dose-response manner [40]. Therefore, loading at $1 \mathrm{~Hz}$ frequency might trigger an osteocytic response. The frequency of mechanical loading affects bone adaption to mechanical loading, i.e., increased frequencies $(1,5$, and $10 \mathrm{~Hz})$ result in more robust bone formation [40], as well as increased bone mass in the equilibrium state in a mathematical trabecular bone remodeling model [41]. Similarly, cortical bone formation is enhanced with increased frequencies up to $5-10 \mathrm{~Hz}$ and plateaus at frequencies beyond $10 \mathrm{~Hz}$ [38]. In our study, with the limitation of limited displacement preservation at frequencies higher than $1 \mathrm{~Hz}$, we utilized mechanical loading at a frequency of $1 \mathrm{~Hz}$. Future studies are needed to investigate the effect of a combination of different loading frequencies and magnitudes on osteocyte mechanoresponsiveness.

Our 3D mechanical loading model was able to maintain high osteocyte viability in both unloaded bone (79\%) and in bone at $24 \mathrm{~h}$ post-culture (76\%), demonstrating that $5 \mathrm{~min}$ mechanical loading at $1600 \mu \varepsilon$ and $1 \mathrm{~Hz}$ did not influence cell viability. This suggested that our model is useful for testing mechanosensitivity of osteocytes with a pre-culture time up to 2 days. Inclusion of a pre-culture period raises the possibility to incubate bone with small molecules, such as mechanoregulating proteins, that will facilitate studies on the role of specific molecules in osteocyte mechanosensing and mechanoresponsiveness. These small molecules likely reach the osteocytes in bone, as indicated by the osteocytes' response to exogenous $1,25(\mathrm{OH})_{2} \mathrm{D}_{3}$ stimulation. Osteocytes showed an upregulation of $C Y P 24 A 1$ gene expression in response to $10^{-7} \mathrm{M} 1,25(\mathrm{OH})_{2} \mathrm{D}_{3}$ treatment. This indicated that they maintained their responsiveness to $1,25(\mathrm{OH})_{2} \mathrm{D}_{3}$, which is a small molecule that can diffuse within the calcified bone matrix to reach the embedded osteocytes. Moreover, gene expression of FGF23 and SOST was observed after 7 days of culture, suggesting that viable osteocytes maintained their osteocyte phenotype. The SOST gene is not expressed in the osteocyte cell line MLO-Y4, and the $F G F 23$ gene is not expressed in isolated human primary osteocytes, but both SOST and FGF23 are expressed in 3D structured and hypoxia-conditioned osteocytes [19, 42, 43]. We also showed that osteocytes in loaded human cortical bone did secrete sclerostin. Therefore, our model appears superior over osteocyte cell lines and mimics in vivo osteocytes in native bone. Mechanosensitive gene expression is a common outcome parameter in studies on mechanosensitivity and responsiveness of osteocytes, and therefore, our results indicate the suitability of our model to study osteocyte mechanoresponsiveness. Taken together, the osteocytes in their native matrix maintained their osteocytic phenotype up to 7 days and responded to changes in their microenvironment. This suggests that our model can be used to study the effect of a changed matrix, such as in patients with bone metabolic disorders, and the effect of small molecules, such as cytokines and hormones, on the mechanoresponsiveness of human osteocyte in their native matrix.

We found that mechanically loaded osteocytes revealed more clear cellular processes and bigger cell bodies than unloaded cells. Mechanical loading might increase osteocyte activity, as well as the connection with other osteocytes and osteoblasts and/or osteoclasts. Osteocyte activity might also have decreased as a result of unloading. Unlike most studies reporting that sclerostin expression in osteocytes is downregulated by mechanical loading [47], we found that sclerostin expression was similar in unloaded osteocytes and in osteocytes loaded at magnitudes up to $8000 \mu \varepsilon$. One possible explanation for this discrepancy is that $24 \mathrm{~h}$ post-culture was still too early, or too late, to observe a change in sclerostin expression in osteocytes. Mechanical loading might have increased osteocyte activity and sclerostin production, while the amount of sclerostin expressed per cell as well as the total amount of sclerostin expressed was decreased. The absolute expression of sclerostin still needs to be quantified in a future study.

Mechanical loading up to $7500 \mu \varepsilon$ did not increase microdamage accumulation. Microdamge in both unloaded and loaded explants might be caused by the surgical procedure and/or by the cutting of bone into explants. Strains of $50-100 \mu \varepsilon$ result in disuse-induced bone remodeling, strains of 1000-1500 $\mu \varepsilon$ lead to operational microdamage, strains above $3000 \mu \varepsilon$ induce the start of bone modeling, and strains above $25,000 \mu \varepsilon$ cause bone fracture in young adult mammals [44]. The loading magnitudes used in the current study were below the fracture threshold, and therefore, the amount of microdamage was similar in unloaded and loaded bone. This indicated that the osteocyte response to mechanical 
loading was affected by the loading magnitude, but not by microdamage. Our results support the hypothesis that our in vitro loading model of osteocytes in their native matrix is a suitable model for studying osteocyte mechanosensitivity and mechanoresponsiveness in bone obtained from patients with metabolic bone diseases.

This study has some limitations. The 3D mechanical loading model cannot be used for trabecular bone since this bone is too thin, too soft, and does not have a regular shape. The bone material used was surgical waste material, which was only available in limited amounts, and cut by a handpiece. Cutting bone could cause microcracks damaging the lacunacanalicular network, disruption of communication between osteocytes and osteoblasts, and decreased osteocyte mechanoresponsiveness. The cellular network in each explant was not strictly the same. Furthermore, explants might not have been obtained from exactly the same bone location, thereby causing possible variation in the bone specifics. The osteocyte mechanoresponsiveness might also have been influenced by donor age and sex.

In conclusion, our 3D mechanical loading model of human osteocytes in their native matrix mimics the osteocyte environment in vivo and is suitable to study osteocyte mechanoresponsiveness in vitro. Whether a changed bone matrix in metabolic bone disease affects osteocyte mechanosensitivity and/or mechanoresponsiveness is still unclear, but our model seems suitable for studying the effect of changed matrix composition, as in human metabolic bone diseases, on osteocyte mechanoresponsiveness, as well as the effect of small molecules on osteocyte mechanosensitivity in drug screening.

Acknowledgements This work was granted by the China Scholarship Council (CSC, No. 201706320330). The authors thank Jan Harm Koolstra, Leo van Ruijven, and Cornelis M. Semeins for their expert technical support and Yumiko van Diest for quantification of microdamage.

Authors' Contributions Chen Zhang, Elisabet Farré-Guasch, Jianfeng Jin, Huib W. van Essen, Jenneke Klein-Nulend, and Nathalie Bravenboer have participated in the conception and design of the manuscript and in the interpretation of the data. Furthermore, each author has been involved in the drafting of the article and concurred with the final version submitted. Nathalie Bravenboer is responsible for the overall content as the guarantor of the manuscript.

Funding This work was granted by the China Scholarship Council (CSC, No. 201706320330).

Data Availability Data and meterial were stored locally at Amsterdam University Medical Centers, Vrije Universiteit Amsterdam, and are available upon request.

\section{Declarations}

Conflict of interest The authors have no conflicts of interest to declare that are relevant to the content of this article.
Ethical Approval All bone explants were obtained with donor's consent. Approval was obtained from the ethics committee of the Amsterdam University Medical Centers (2016.105). The procedures used in this study adhere to the tenets of the Declaration of Helsinki.

Consent to Participate Not applicable.

Consent for Publication Not applicable.

Open Access This article is licensed under a Creative Commons Attribution 4.0 International License, which permits use, sharing, adaptation, distribution and reproduction in any medium or format, as long as you give appropriate credit to the original author(s) and the source, provide a link to the Creative Commons licence, and indicate if changes were made. The images or other third party material in this article are included in the article's Creative Commons licence, unless indicated otherwise in a credit line to the material. If material is not included in the article's Creative Commons licence and your intended use is not permitted by statutory regulation or exceeds the permitted use, you will need to obtain permission directly from the copyright holder. To view a copy of this licence, visit http://creativecommons.org/licenses/by/4.0/.

\section{References}

1. Bonewald LF, Johnson ML (2008) Osteocytes, mechanosensing and Wnt signaling. Bone 42:606-615. https://doi.org/10.1016/j. bone.2007.12.224

2. Klein-Nulend J, van Oers RF, Bakker AD, Bacabac RG (2015) Bone cell mechanosensitivity, estrogen deficiency, and osteoporosis. J Biomech 48:855-865. https://doi.org/10.1016/j.jbiomech. 2014.12.007

3. Klein-Nulend J, Bakker AD, Bacabac RG, Vatsa A, Weinbaum S (2013) Mechanosensation and transduction in osteocytes. Bone 54:182-190. https://doi.org/10.1016/j.bone.2012.10.013

4. Delgado-Calle J, Sato AY, Bellido T (2017) Role and mechanism of action of sclerostin in bone. Bone 96:29-37. https://doi.org/10. 1016/j.bone.2016.10.007

5. Sun Q, Choudhary S, Mannion C, Kissin Y, Zilberberg J, Lee WY (2017) Ex vivo construction of human primary 3D-networked osteocytes. Bone 105:245-252. https://doi.org/10.1016/j.bone. 2017.09.012

6. Sun Q, Choudhary S, Mannion C, Kissin Y, Zilberberg J, Lee WY (2018) Ex vivo replication of phenotypic functions of osteocytes through biomimetic 3D bone tissue construction. Bone 106:148 155. https://doi.org/10.1016/j.bone.2017.10.019

7. Robling AG, Niziolek PJ, Baldridge LA, Condon KW, Allen MR, Alam I, Mantila SM, Gluhak-Heinrich J, Bellido TM, Harris SE, Turner CH (2008) Mechanical stimulation of bone in vivo reduces osteocyte expression of Sost/sclerostin. J Biol Chem 283:58665875. https://doi.org/10.1074/jbc.M705092200

8. Spatz JM, Wein MN, Gooi JH, Qu Y, Garr JL, Liu S, Barry KJ, Uda Y, Lai F, Dedic C, Balcells-Camps M, Kronenberg HM, Babij P, Pajevic PD (2015) The Wnt inhibitor sclerostin ss up-regulated by mechanical unloading in osteocytes in vitro. $\mathrm{J}$ Biol Chem 290:16744-16758. https://doi.org/10.1074/jbc.M114.628313

9. Robling AG, Bonewald LF (2020) The osteocyte: New insights. Annu Rev Physiol 82:485-506. https://doi.org/10.1146/annurev. med.051308.111339

10. Bonewald LF, Wacker MJ (2013) FGF23 production by osteocytes. Pediatr Nephrol 28:563-568. https://doi.org/10.1007/ s11154-015-9318-Z 
11. Blau JE, Collins MT (2015) The PTH-vitamin D-FGF23 axis. Rev Endocr Metab Disord 16:165-174. https://doi.org/10.1007/ s00467-012-2309-3

12. Bergwitz C, Juppner H (2010) Regulation of phosphate homeostasis by PTH, vitamin D, and FGF23. Annu Rev Med 61:91-104. https://doi.org/10.1007/978-1-61779-108-6_15

13. Juffer P, Jaspers RT, Lips P, Bakker AD, Klein-Nulend J (2012) Expression of muscle anabolic and metabolic factors in mechanically loaded MLO-Y4 osteocytes. Am J Physiol Endocrinol Metab 302:E389-395. https://doi.org/10.1152/ajpendo.00320.2011

14. Li J, Rose E, Frances D, Sun Y, You L (2012) Effect of oscillating fluid flow stimulation on osteocyte mRNA expression. J Biomech 45:247-251. https://doi.org/10.1016/j.jbiomech.2011.10.037

15. Kogawa M, Wijenayaka AR, Ormsby RT, Thomas GP, Anderson PH, Bonewald LF, Findlay DM, Atkins GJ (2013) Sclerostin regulates release of bone mineral by osteocytes by induction of carbonic anhydrase 2. J Bone Miner Res 28:2436-2448. https:// doi.org/10.1002/jbmr.2003

16. Chalil S, Jaspers RT, Manders RJ, Klein-Nulend J, Bakker AD, Deldicque L (2015) Increased endoplasmic reticulum stress in mouse osteocytes with aging alters Cox-2 response to mechanical stimuli. Calcif Tissue Int 96:123-128. https://doi.org/10.1007/ s00223-014-9944-6

17. Kamioka H, Miki Y, Sumitani K, Tagami K, Terai K, Hosoi K, Kawata T (1995) Extracellular calcium causes the release of calcium from intracellular stores in chick osteocytes. Biochem Biophys Res Commun 212:692-696. https://doi.org/10.1006/bbrc. 1995.2024

18. Zhao W, Byrne MH, Wang Y, Krane SM (2000) Osteocyte and osteoblast apoptosis and excessive bone deposition accompany failure of collagenase cleavage of collagen. J Clin Invest 106:941949. https://doi.org/10.1172/JCI10158

19. Choudhary S, Sun Q, Mannion C, Kissin Y, Zilberberg J, Lee WY (2018) Hypoxic three-dimensional cellular network construction replicates ex vivo the phenotype of primary human osteocytes. Tissue Eng Part A 24:458-468. https://doi.org/10.1089/ten.TEA. 2017.0103

20. Johnson RW, Sowder ME, Giaccia AJ (2017) Hypoxia and bone metastatic disease. Curr Osteoporos Rep 15:231-238

21. Wenger RH, Kurtcuoglu V, Scholz CC, Marti HH, Hoogewijs D (2015) Frequently asked questions in hypoxia research. Hypoxia (Auckl) 3:35-43. https://doi.org/10.2147/HP.S92198

22. Ito N, Findlay DM, Anderson PH, Bonewald LF, Atkins GJ (2013) Extracellular phosphate modulates the effect of 1alpha,25dihydroxy vitamin D3 (1,25D) on osteocyte like cells. J Steroid Biochem Mol Biol 136:183-186. https://doi.org/10.1016/j.jsbmb. 2012.09.029

23. Saito H, Maeda A, Ohtomo S, Hirata M, Kusano K, Kato S, Ogata E, Segawa H, Miyamoto K, Fukushima N (2005) Circulating FGF-23 is regulated by 1alpha,25-dihydroxyvitamin D3 and phosphorus in vivo. J Biol Chem 280:2543-2549. https://doi.org/ 10.1074/jbc.M408903200

24. Lieben L, Carmeliet G (2013) Vitamin D signaling in osteocytes: effects on bone and mineral homeostasis. Bone 54:237-243. https://doi.org/10.1016/j.bone.2012.10.007

25. Jones G, Prosser DE, Kaufmann M (2012) 25-Hydroxyvitamin D-24-hydroxylase (CYP24A1): its important role in the degradation of vitamin D. Arch Biochem Biophys 523:9-18. https://doi. org/10.1016/j.abb.2011.11.003

26. Bakker AD, Silva VC, Krishnan R, Bacabac RG, Blaauboer ME, Lin YC, Marcantonio RA, Cirelli JA, Klein-Nulend J (2009) Tumor necrosis factor alpha and interleukin-1beta modulate calcium and nitric oxide signaling in mechanically stimulated osteocytes. Arthritis Rheum 60:3336-3345. https://doi.org/10.1002/art. 24920
27. Bakker AD, Kulkarni RN, Klein-Nulend J, Lems WF (2014) IL-6 alters osteocyte signaling toward osteoblasts but not osteoclasts. J Dent Res 93:394-399. https://doi.org/10.1177/0022034514 522485

28. Pathak JL, Bravenboer N, Luyten FP, Verschueren P, Lems WF, Klein-Nulend J, Bakker AD (2015) Mechanical loading reduces inflammation-induced human osteocyte-to-osteoclast communication. Calcif Tissue Int 97:169-178. https://doi.org/10.1007/ s00223-015-9999-z

29. Pathak JL, Bakker AD, Luyten FP, Verschueren P, Lems WF, Klein-Nulend J, Bravenboer N (2016) Systemic inflammation affects human osteocyte-specific protein and cytokine expression. Calcif Tissue Int 98:596-608. https://doi.org/10.1007/ s00223-016-0116-8

30. Hemmatian H, Jalali R, Semeins CM, Hogervorst JMA, van Lenthe GH, Klein-Nulend J, Bakker AD (2018) Mechanical loading differentially affects osteocytes in fibulae from lactating mice compared to osteocytes in virgin mice: Possible role for lacuna size. Calcif Tissue Int 103:675-685. https://doi.org/10.1007/ s00223-018-0463-8

31. Fazaeli S, Ghazanfari S, Everts V, Smit TH, Koolstra JH (2016) The contribution of collagen fibers to the mechanical compressive properties of the temporomandibular joint disc. Osteoarthritis Cartilage 24:1292-1301. https://doi.org/10.1016/j.joca.2016.01. 138

32. Berendsen AD, Smit TH, Walboomers XF, Everts V, Jansen JA, Bronckers ALJJ (2009) Three-dimensional loading model for periodontal ligament regeneration in vitro. Tissue Eng Part C Methods 15:561-570. https://doi.org/10.1089/ten.TEC.2008.0336

33. Turner CH, Burr DB (1993) Basic biomechanical measurements of bone: a tutorial. Bone 14:595-608. https://doi.org/10.1016/ 8756-3282(93)90081-k

34. Jahn K, Stoddart MJ (2011) Viability assessment of osteocytes using histological lactate dehydrogenase activity staining on human cancellous bone sections. Methods Mol Biol 740:141-148. https://doi.org/10.1146/annurev-physiol-021119-034332

35. van der Meijden K, Buskermolen J, van Essen HW, Schuurman T, Steegenga WT, Brouwer-Brolsma EM, Langenbach GEJ, van Ruijven LJ, den Heijer M, Lips P, Bravenboer N (2016) Long-term vitamin D deficiency in older adult C57BL/6 mice does not affect bone structure, remodeling and mineralization. J Steroid Biochem Mol Biol 164:344-352. https://doi.org/10.1016/j.jsbmb.2015.09. 004

36. Bouxsein ML, Boyd SK, Christiansen BA, Guldberg RE, Jepsen KJ, Muller R (2010) Guidelines for assessment of bone microstructure in rodents using micro-computed tomography. J Bone Miner Res 25:1468-1486. https://doi.org/10.1002/jbmr.141

37. Landrigan MD, Li J, Turnbull TL, Burr DB, Niebur GL, Roeder RK (2011) Contrast-enhanced micro-computed tomography of fatigue microdamage accumulation in human cortical bone. Bone 48:443-450. https://doi.org/10.1016/j.bone.2010.10.160

38. Warden SJ, Turner CH (2004) Mechanotransduction in the cortical bone is most efficient at loading frequencies of $5-10 \mathrm{~Hz}$. Bone 34:261-270. https://doi.org/10.1016/j.bone.2003.11.011

39. Turner CH, Yoshikawa T, Forwood MR, Sun TC, Burr DB (1995) High frequency components of bone strain in dogs measured during various activities. J Biomech 28:39-44. https://doi.org/10. 1016/0021-9290(95)80005-0

40. Hsieh YF, Turner CH (2001) Effects of loading frequency on mechanically induced bone formation. J Bone Miner Res 16:918924. https://doi.org/10.1359/jbmr.2001.16.5.918

41. Kameo Y, Adachi T, Hojo M (2011) Effects of loading frequency on the functional adaptation of trabeculae predicted by bone remodeling simulation. J Mech Behav Biomed Mater 4:900-908. https://doi.org/10.1016/j.jmbbm.2011.03.008 
42. Woo SM, Rosser J, Dusevich V, Kalajzic I, Bonewald LF (2011) Cell line IDG-SW3 replicates osteoblast-to-late-osteocyte differentiation in vitro and accelerates bone formation in vivo. $\mathrm{J}$ Bone Miner Res 26:2634-2646. https://doi.org/10.1002/jbmr.465

43. Stern AR, Stern MM, Van Dyke ME, Jahn K, Prideaux M, Bonewald LF (2012) Isolation and culture of primary osteocytes from the long bones of skeletally mature and aged mice. Biotechniques 52:361-373. https://doi.org/10.2144/0000113876
44. Frost HM (2003) Bone's mechanostat: a 2003 update. Anat Rec A Discov Mol Cell Evol Biol 275:1081-1101. https://doi.org/10. 1002/ar.a.10119

Publisher's Note Springer Nature remains neutral with regard to jurisdictional claims in published maps and institutional affiliations. 